
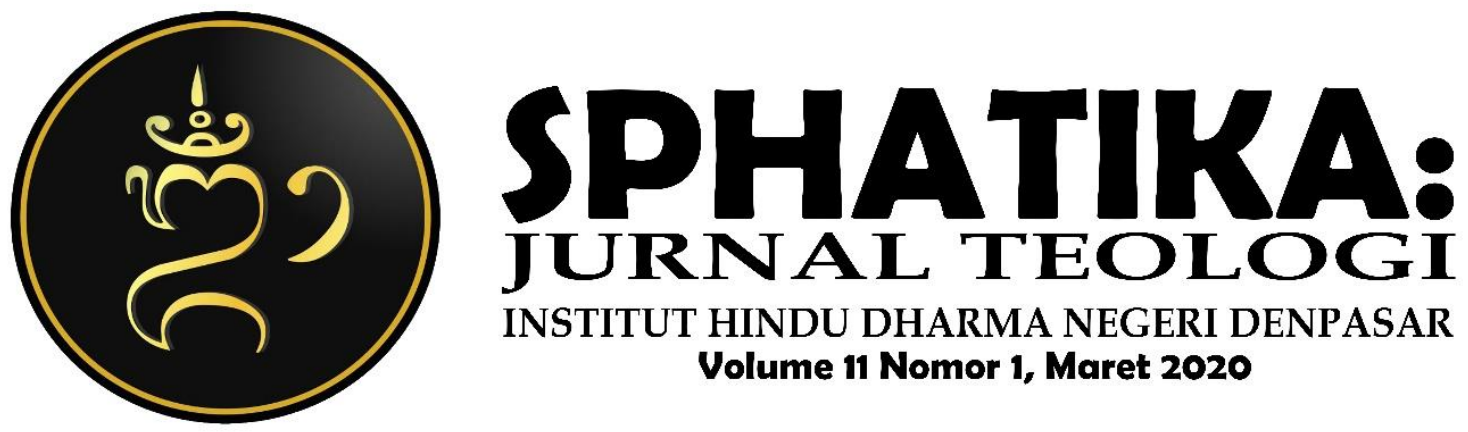

\title{
MANTRA ATHARWA VEDA SEBAGAI KEDAMAIAN DAN PENCEGAH PENDERITAAN DALAM KEHIDUPAN MANUSIA
}

\author{
Ni Ketut Puspita Sari \\ I Nyoman Mandiasa
}

\section{Institut Hindu Dharma Negeri Denpasar}

\begin{tabular}{|c|c|}
\hline Keywords: & ABSTRACT \\
\hline Mantra, Atharwa Veda & $\begin{array}{l}\text { The Vedas which are the most important } \\
\text { scriptures in Hinduism contain a collection of } \\
\text { revelations which are compiled and systematically } \\
\text { rearranged according to their purpose. All the Vedas } \\
\text { referred to as the Samhita and Sruti Mantra comprise } \\
\text { four groups or the Chess of the Vedic Samhita. The sruti } \\
\text { means revelation, Samhita which means set. The four } \\
\text { groups (samhita) are: Rg Veda, Yajna Veda, Sama Veda } \\
\text { and Atharwa Veda, three of the four groups of Vedas are } \\
\text { called Tri Widya or Vedic Trayi, so Atharwa Veda is } \\
\text { classified as the fourth or final Veda, traditionally the } \\
\text { Atharwa Veda is recognized as the Hindu scripture of } \\
\text { the Hindu religion. included in the sruti Veda (Sruti } \\
\text { Veda). Atharwa Veda contains things that are } \\
\text { commonly known by the people or people and not so } \\
\text { with the contents of the Rg Veda its contents are more } \\
\text { secular compared to other Vedas that specialize in } \\
\text { teaching about religious worship, Atharwa Veda } \\
\text { teachings mainly teach how people can overcome the } \\
\text { peace that results in division and suffering in human } \\
\text { life, many interpreted to contain wisdom about worldly } \\
\text { life while the way of worship is not a basic creed. }\end{array}$ \\
\hline
\end{tabular}




\section{PENDAHULUAN}

Veda yang sebagaiamana kita kenal sekarang pada umunya merupakan kumpuan tulisan yang memuat berbagai pandangan dan pengetahuan penting yang diperlukan oleh umat Hindu. Veda memuat pandangan filsafat Hindu dan memuat sumber pikiarn yang mempengaruhi pandangan dan sikap hidup umat Hindu. Secara tradisional dinyatakan bahwa Veda adalah kitab suci bagi Hindu dan karena itu Veda mempengaruhi segala sikap pandangan Hindu itu, Veda sebagai sumber dharma dan agama serta Veda dijadikan dasar bagi umat Hindu. Telah dijelaskan di dalam Rg Veda, bahwa seluruh Veda yang disebut Mantra Samhita atau sruti terdiri atas empat kelompok atau catur Veda samhita ,sruti Terjemahannya: wahyu, Samhita Terjemahannya: himpunan .Keempat kelompok itu adalah Rg Veda, Yajur Veda, sama Veda dan Atharwa Veda. Tiga dari empat kelompok Veda ini disebut Veda Trayi ,sehingga Atharwa Veda tergolong sebagai Veda yang keempat atau terakhir Melihat isinya tampaknya mantra-mantra Atharwa Veda sebagian besar diangkat dari mantra-mantra yang terdapat di dalam Rg Veda, akan tetapi ada perbedaan dari Rg Veda karena bagian yang dihimpunnya pun isinya mengenai cara memusnahkan atau menawar penyebab- penyebab penyakit baik karena gangguan alam, buatan manusia atau lainnya yang menyebabkan pederitaan dan ketidakdamaian. Ajaran Atharwa Veda terutama mengajarkan bagaiamana orang dapat mengatasi, mencegah penyakit yang berujung penderitaan dan ketidakdamaian tersebut.

Kehidupan manusia perlu menyikapi kemajuan zaman dengan berpikir dewasa, bijak dan jangan sampai tenggelam dan larut dengan kemajuan zaman tanpa control. Hidup semakin nikmat berkat perkembangan teknologi yang berbasis materi. Materialisme yang berujung atheisme, terallu menikmati kehidupan yang bergelamor dengan material, tidak mengatur pola makan, tanpa disadari menjadikan manusia tak peduli dengan spiritualisme alami. Manusia menjadi tak terkendali dan hanya mengumar amarah, kebencian, iri hati, emosi, mengandalkan kekuasaan, kekayaan. Karena keserakahan mereka tidak bisa menjaga dan mengunankan alam dengan bijak,yang berujung menimbulkan ketidakdamiaan dalam Tri hita krana .Karna kebencian mereka pun menyelesaikan persoalan dengan 
kekerasan, guna -guna (ilmu hitam), hingga berujung penderitaan dan kematian. Tidak pernah ada yang tau akan rahasia kehidupan manusia baik rejeki, jodoh dan kematian. Sementara di dunia ini manusia saling berpacu dan berlomba meraih semuanya. Penderitaan, ketidakdamaian, penderitaan yang berujung kematian, sejatinya terdapat cara untuk mengatasinya, menghilangkannya, menjauhkannya jika kita paham dan percaya dengan ilmu spiritual dan melakukan persembhayangan kehadapan tuhan yang maha esa beserta manifestasinya serta mempercayai ajaran tuhan dengan mempelajari Veda yang tergolong Atharwa Veda yang mengajarkan bagaimana orang dapat mengatasi penderitaan, penyakit yang berujung ketidakdamaian. Jika ingin kehidupan kita mendapatkan kedamaian kita sebagai manusia harus hidup dengan selaras, asih asuh, tidak serakah, menjalankan Tri Hita Karana agar tidak menimbulakan perpecahan, keserakahan, dan ketidakdamaian di dalam hidup.

\section{PEMBAHASAN}

\section{Ajaran Atharwa Veda}

AtharvaVeda berasal dari bahasa sansekerta yang berakar dari kata atharvān, nama ini berasal dari nama seorang Rsi, dan Veda yang berarti pengetahuan adalah sastra suci bagi umat Hindu yang memiliki pandangan dan pengetahuan yang penting. Atharawa Veda diakui sebagai kitab suci Hindu sehingga sampai sekarang apabila orang mengatakan Veda Sruti maka yang di maksud adalah Catur Veda itu, Atharwa Veda memiliki nama himpunan mantra dihimpun oleh keluarga Maha Rsi Atharwan. Rupa-rupanya nama Atharwa Veda itu berasal dari gelar maha rsi atharwan yang bertanggung jawab atas terhimpunnya mantra-mantra itu. Melihat isi dari Athrawa Veda yang tampaknya mantra-mantra Atharwa Veda sebagian besar diangkat dari mantra-magra yang terdapat di dalam Rg Veda. Namun sedikit berbeda dari Rg Veda karena bagian yang dihimpun isinya mengenai cara memusnahkan atau menawar penyebab-penyebab penyakit baik karena gagngguan alam, buatan manusia, atau lainnya.

Terdapat 9 sakha atau (resensi atau cabang tentang AtharvaVeda, yaitu Paippalāda, Dānta, Pradānta, Snāta, Snauta, Brahmadāvala, Śaunaka, Devadarśani, 
dan Caranavidyā. Namun saākhā yang masih bertahan hingga kini adalah Śaunakiya dan Paippalāda. Atharwawda ini disusun dengan vedic Sanskrit dan berisikan 730 nyanyian pujian dengan 6.000 mantra yang dibagi menjadi sekitar 20 buku setengah dari buku ini mengambil ayat-ayat Rg Veda, dan kecuali untuk Buku 15 dan 16, teks ini bersikan puisi - puisi yang menyebarkan Veda. terdapat Dua resensi atau cabang teks yang terdapat hingga sekarang, yaitu Paippalāda dan Śaunakìya akan tetapi manuskrip ini tepercaya dari edisi Paippalada dan diyakini telah hilang, ada pula versi yang terpelihara dengan baik ditemukan di antara kumpulan manuskrip terdapat di daun palem di Odisha pada tahun 1957.

\section{- Paippalda Samhita}

Ini selalu dikaitkan dengan sebuah jilid yakni "Prapancahrdaya". Seperti tiaptiap volume, orang suci pertama dari Samhita ini adalah ahli metafisika yang terkenal "pippalada" hanya sebuah salinan dari Samhita ini yang terdiri dari dua puluh kanda yang di temukan di Kashmir hal itu terdapat di dalam naskah Sarada yang berisikan lagu pujian. Lagu pujian ini telah diterima sebagai lagu pujian pertama dari Pappalada Samhita di dalam Chandogya mantra Bhasya, Saunaka Samhita umunnya terdapat lagu pujian ini sebagai lagu-lagu pujian pertama pada sukta kesembilan dan kanda pertama.

\section{- Sannaka Samhita}

Gophata Brahmana dan Atharwa Samhita seperti pada umunya menyinggung pada cabang saunaka ini. Hal ini dibagi kedalam dua puluh buku atau kanda yang juga di bagi ke dalam Anuvaka dan selanjutnya ke dalam sukta yang semuanya kira-kira 730. Atharwa Veda berisikan ajaran hal-hal yang umum di kenal oleh rakyat umum dan tidak demikian halnya dengan isi Rg Veda. Bahkan isinya lebih bersifat seculer dibandingkan dengan Veda lainnya yang mengkhususkan memuat ajaran ibadah agama. Oleh karena itu maka Athrawa Veda isinya banyak dapat ditafsirkan bierisikan ajaran kebijaksanaaan-kebijaksanaan tentang kehidupan duniawi dan ritual. Rsi Wasistha dikenal sebagai pendukung dalam ajarana atharwa Veda terutama karena mengajarkan bagaimana orang dapat mengatasi ,menghilangankan segala penyakit baik dari gangguan alam, buatan 
manuasia(guna-guna) yang menyebabkan penderitaan, kegelapan, ketidakdamaian dan kematian

Atharwa Veda ini sejatinya menguraikan mengenai penerapan dari kedua jenis upacara yaitu penegasan dengan sempurna dan upacara ritual-ritual.Suatu hal

penting yang khusus dari penerapan tindakan-tindakan Santika-Paustika dan Tulapurusa Mahadana dan lainnya. Sesuatu hal yang perlu di catat adalah lagu-lagu pujian dari Atharvan adalah dengan sederhana, lembut dan penegasan dan lagu puji-pujian dari para Angira merupakan ilmu gaib, lagu-lagu pujian Atharwa Veda termasuk ke dalam kelompok-kelompok berbeda seperti lagu-lagu pujian dengan maksud untuk mendapatkan kehidupan yang panjang untuk mengampuni dosadosa yang dilakukannya

\section{Mantra untuk kedamaian dan mencegah penderitaan dalam ajaran Athrawa}

\section{Veda}

Secara tradisional semua Veda itu dihimpun dalam empat himpunan yang dapat diartikan sebagai catur Veda Samhita yaitu Rg Veda Samhita, Sama Veda Samhita, Yajur Veda samhita, Atharwa Veda samhita. Dari keempat kelompok ini dikatakan bahwa atharwa Veda dianggap paling belakang dan terakhir bahkan karena paling terakhir sering tidak diperhitungkan dalam sejarah kehidupan sastra, yang hanya terkenal adalah tiga kelompok pertama yang sering ketiga-tiganya dikenal sebagai Veda traya ,keempat kelompok ini teramsuk dalam kelompok mantra. Ketika kita menjumpai kata "Mantra", pikiran kita mengenal kata itu sendiri yang dapat bearrti banyak.Secara umum bahwa mantra dalam hubungannya dengan Veda adalah nama lain yang diberikan kepada kitab Veda itu. Demikian juga asal mula penamaan manra untuk Veda adalah karena kenyataan bahwa Veda itu sendiri adalah mantra atau hymne atau bahasa puisi.

Di Dalam kamus bahasa sansekerta kata mantra diartikan sebagai "alat pikiran", sabda, kitab suci, hymne, atau lagu-lagu pujaan dan di dalam Atharwa Veda mantra diartikan sebagai lafal-lafal suci yang mempunyai kekuatan gaib atau mistik. Selanjutnya di dalam sastra kata mantra berkembang demikian rupa sehingga berarti musyawarah, ketetapan, rahasia, nasehat-nasehat dan lainnya 
Setiap mantra dinyatakan sebagai manifestasi bentuk (rupa) Brahman.Pikiran merupakan asal dari kata mantra itu karena mantra berasal dari kata manana(pikiran ) dan dari pikiran itu melahirkan pengertian kebenaran yang esa itu. Tra yang berasal dari kata trana yang berarti kebebasan dan dengan pembebasan itu dengan sendirinya adalah pembebasan dari penderitaan (sengsara). Di dalam Atharwa Veda yang berisikan ajaran ilmu spiritual yang msitik terdapat mantra yang memiliki kekuatan untuk menghindari, menghilangkan manusia dari penderitaan, penyakit yang berujung kesengsaraan, ketidakdamaian dan kematian. Megingat maraknya penyakit yang terdapat di kehidupan manusia, baik penyakit alam maupun buata manusia yang karena didasari dari keserakahan ,kemarahan, emosi ataupun iri hati dan dendam untuk menghindari penyakit yang akan membawa penderitaan tersebut di dalam ajaran Atharwa Veda terdapat mantra untuk hal itu. Adapun mantra di dalam Atharwa Veda yang dapat menghindari penderitaan dan berumur panjang, yakni:

Upa priyam panipnatam yuvanamahutivrdham,

Agnma bibhrato namo dirghamayuh krnotu me.

Terjemahannya:

AtharvaVeda VII.32.1

Kepada yang dikasihi,pencipta keajaiban (senantiasa) muda, yang pijian baginya senantiasa makin melimpah, kami memohon, (kepada yang patut menerimanya) penghormatan semoga ia melimpahkan umur panjang bagiku.

Mantram agar melenyapkan perasaan yang iri hati untuk kedamaian.

Angerivasya dahati davasya dahatan prthak,

Etametasyersyamudnagnimiva samaya

Atharwa Veda VII.45.1

Terjemahannya:

Ia yang bagaikan api menyala -nyala ,bagaikan api yang menyala-nyala dengan dahsyatnya ,rasa iri hati orang itu lenyapkanah, bagaikan api yang tersiram air.

Perasaan yang iri hati bagaikan api yang membara dan menyala-nyala, peradaan itu hanya dapat di hilangkan dan diredakan dengan kesadaran, intropeksi diri, tenang bagaikan air hingga menjadi padam dan hilang. Adapun mantra di dalam Atharwa Veda yang dapat menghindari dari amarah dan menimbulkan kedamaian di dalam kehidupan manusia. 
Nainam prapnoti saphato

Na krtya nabhisocanam

Nainam viskandhamasnute

Yastva bibhartyanjana

AtharvaVeda IV.9.5

Terjemahannya:

Percaya kepada Tuhan menyebabkan tak mudah marah, Percaya kepada Tuhan tidak akan menyakiti mahluk lain, mereka juga tidak akan mendapatkan kesedihan, hidup mereka akan terlepas dari kesulitan.

Manusia hendaknya percaya terhadap Tuhan. Percaya kepada Tuhan berarti dia menerima Tuhan sebagai pelindungnya. Orang yang berada dalam perlindungan Tuhan akan memandangdan merasakan suka dan duka itu sama saja. Karena itu mereka tidak akan pernah bersedih atau susah. Mereka lalu mudah mengendalikan diri dan tidak akan mudah menjadi marah. Orang itupun tidak akan mudah menyakiti mahluk lainnya.

Masih merujuk kepada Mantra Atharva Veda tersebut, merujuk kepada enam langkah sesuai dengan apa yang dinyatakan dalam Atharva Veda tersebut yang akan membawa sebuah kedamaian. Sebagai dasar pandangan dan pedoman untuk menata hidup dan kehidupan kita, sebagai upaya untuk menciptakan kedamaian / keharmonisan di Bumi. Terdapat 6 perilaku yang mencapai kedamaian trtuang pada kitab Atharwa Veda, yaitu.

Satyam brhadrtamugram diksa tapo brahma yajnah prthivim dharayani, sa no bhutasya bhavyasya patnyurum lokam prthivi nah krnotu.

ArthawaVeda XII.1.1

Terjemahannya:

Kebenaran agung dan kokoh, penyucian, penebusan kesalaahn brahman dan penyembahan suci yang menunjang keberadaan bumi ini, semoga ia melimpahkan kebahgiaan pada kita, yakni ia yang merupakan penguasa bagi yang telah ataupun akan ada. semoga dunia ini menyediakan tempat yang lapang dan leluasa bagi kita.

Adapun penjelasan dari mantra ArthawaVeda XII.1.1 tersebut di atas adalah sebagai berikut:

a. Satyam = perilaku kebenaran, kebajikan, keadilan

b. Rtam = Hukum alam dan hukum duniawi, prilaku untuk tidak merusak sistem hukum. 
c. Diksa = Kesucian, penyucian,nilai kesucian akan terlihat jika kita mempelajari sastra agama.

d. Tapa $=$ Pengekangan diri, pengendalian indria atau berprilaku dengan menahan diri dari hawa nafsu yang berlebihan. Dalam hidup dan kehidupan ini dibutuhkan sebuah pengendalian diri, agar tidak terjerumus kelembah penderitaan Sehingga dalam hal ini pengendalian diri sangat penting, sehingga konsep mensorgakan (kedamaian abadi) dunia ini dapat tercapai.

e. Brahma = Berdoa, melantunkan kidung-kidung suci/gita, prilaku yang selalu melantunkan doa / gita untuk memberikan rasa, situasi kesucian pada diri sendiri, orang lain dan seluruh sekalian alam.

f. Yajñ $=$ Pengorbanan yang berprilaku tulus dan ikhlas hingga mencapi kedamaian dan kesucian.

Mantra-mantra dari Atharwa Veda menunjukan sebuah gaya ungkapan yang berada di dalam memenuhi pernyataan-pernyataan,ya. Teks sutra dari Atharwa Veda adalaah Kausika Sutra .Penerapan khusus dari lagu-lagu pujian itu telah dijelaskan.Atharwa Veda kini dikatakan sebagai pemahaan terhadap ilmu gaib, akan tetapi itu merupakan kesalahn, sejumlah penerapan-penerapan gaib telah disebutkan di dalam Atharwa Veda untuk menghindari dari rintangan-rintangan dan penindasan dari kejahatan. Adapun mantra untuk melawan segala penyakit yang ada di tubuh disebutkan dalam mantra Atharwa Veda sebagai berikut.

Harimanan te angebhyo'pvnamantarodarat,

Yaksmodhamantaratmano bahirmirmn trayamahe

Atharwa Veda VIII.8.9

Terjemahannya:

Penyakit kuning yang menyerang anggota tubuhmu apa yang menyerang organ-organ dalam perutmu, yaksma yang menyerang dirimu dari dalam kami halau dengan pelafalan mantra-mantra

Dalam hubungan inilah peranan dan fungsinya mantra itu dilihat dalam Veda. Hal ini perlu diyakini larena dijelaskan; lebih jauh bahwa untuk mencapai ketempat tujuan yaitu Tuhan Yang Maha Esa yang akan dipikirkan dalam sembhyang itu, sarana yang terpenting ialah mantra itu. Ketepatan pengucapan lagu 
atau mantra itu dapat mengerakan kekuatan yang paling dasar dalam diri manusia dan karena itu dikatakan dapat mengundag segala kekuatan alam yang ada. Untuk menguasai suatu mantra sehinga menjadi seorang yang dinyatakan siddhi mantra memerlukan latihan dan bimbingan. Tinggi rendahnya intonasi yang teratur itulah yang kemudian dikenal dengan nama chanda, chanda tidak lain adalah pengucapan mantra menurut aturan atau aturan itu sendiri yang dipergunakan sebagai dasar penyusunan kata-kata mantra itu.

\section{PENUTUP}

Untuk mengawasi atau membentengi diri baik secara individu atau komunitas dalam kehidupan manusia yang beragama agar dijauhi oleh kegelapan dan tidak terjerumus kepada suasana kegelapan ,dibutuhkan kenyakinan (sraddha) dan bhakti ( pemujaan) yang kuat dan didasari dengan keikhlasan serta melantunkan mantra dengan tenang, tepat, ataupun mengimplementasikan prinsip - prinsip dasar yaitu tattwa, susila, upacara yang berdasarkan kitab suci ataupun sastra suci agama Hindu yang lainnya dalam kehidupan sehari - hari seperti pesanpesan nilai yang harus diimplementasikan dalam kehidupan sehari hari pedoman untuk menata kehidupan ini yang pada akhirnya akan bermuara pada hakekat sesungguhnya, yaitu umat manusia meerlukan peraturan, keharmonisan, ketertiban dan kedamaian yang terdapat di dalam ajaran agama Hindu .hal ini dikemasnya dan dijadikan satu dengan sebuah tujuan hidup yaitu "moksartam jagadhita ya ca iti dharma" hingga menemukan kedamaian, kebahagiaan dan dijauhkan dari penderitaan .

\section{DAFTAR PUSTAKA}

Dipl Taniputera Ivan, 2005. Atharwa Veda Samhita II. Surabaya: Paramitha Pudja, Gde. 1979. Rg Veda Mandala I. Denpasar: Pengadaan Kitab Suci Hindu. Sugiarto, R. 1988. Atharwa Veda Sruti.

Prabhupada, Swami. 2006. Bhagavadgita Menurut Aslinya. Perpustakaan Nasional. 